\title{
Adults' perception of native and nonnative vowels: Implications for the perceptual magnet effect
}

\author{
ELAINA M. FRIEDA, AMANDA C. WALLEY, JAMES E. FLEGE, and MICHAEL E. SLOANE \\ University of Alabama, Birmingham, Alabama
}

\begin{abstract}
Two experiments were conducted to evaluate the perceptual magnet effect. In Experiment 1, American English speakers representing diverse dialects were presented with a fine-grained set of stimuli (varying in just noticeable differences for $F 1$ and $F 2$ ) and indicated whether they heard "/i /" or "not /i/," thus delimiting the $/ \mathrm{i} /$ portion of the vowel space for individual subjects. Then these same subjects selected their own $/ \mathrm{i} /$ prototype with a method-of-adjustment procedure. The data from this experiment were used to synthesize customized prototype and nonprototype stimulus sets for Experiment 2 . In Experiment 2, 24 of our original 37 subjects completed a discrimination task for each of three conditions, in which vector stimuli varied from the subject's prototype, the nonprototype, or a foreign vowel $(/ \mathrm{y} /)$ in 15-mel steps. Subjects displayed higher discrimination, as indexed by $d^{\prime}$, for the nonprototype condition than they did for both the prototype and the foreign conditions. In addition, discrimination was better for variants further away from the referent in each condition. However, discrimination was not especially poor for stimuli close to subjects' individual prototypes-a result that would have yielded the strongest support for the operation of a magnet effect. This negative finding, together with other aspects of our results, raises problems for any theory of vowel perception that relies solely on "onesize-fits-all" prototype representations.
\end{abstract}

According to one prominent theory of category representation, perceptual-cognitive categories are structured in terms of prototypes, or abstract and ideal summary representations of those features needed for category membership (see, e.g., Smith \& Medin, 1981). These representations act as cognitive reference points against which actual objects are evaluated (Rosch, 1975). That is, on the basis of the extent to which they overlap or share features with the prototype, some objects are perceived or judged to be better exemplars of a category than are others. For example, in most people's estimation, a robin is a more prototypic exemplar of the category bird than is an ostrich.

Prototype theory has recently been influential in guiding research on speech representation and processing. Kuhl (1991, 1993a, 1993b, 1993c), in particular, has elaborated on this theory and proposed that the phonetic categories of one's native language are represented in long-term memory as prototypes. According to her native language magnet (NLM) theory, these prototypes begin to function in early

Support for this research was provided by the National Institute for Child Health and Development (HD30398) and the National Institute for Deafness and Other Communicative Disorders (DC00257). We thank three anonymous reviewers and Robert $\mathrm{E}$. Remez for helpful comments on a previous version of this paper. Correspondence concerning this article should be addressed to A. C. Walley, Department of Psychology, 415 Campbell Hall, University of Alabama, Birmingham, AL 35294 (e-mail: awalley@uab.edu) or to J. E. Flege, Department of Rehabilitation Sciences, School of Health Related Professions, Box 503, UAB Station, Birmingham, AL 35294 (e-mail: flegeje@rehabsci.shrp.uab.edu). infancy as perceptual magnets by attracting or assimilating nearby members of the same phonetic category. The result is a warping of the psychoacoustic space; that is, the perceived distance between a given prototype and neighboring stimuli is "shrunk," whereas the perceived distance between more distant members or poorer exemplars of the category is "stretched." In this way, perceptual distinctions in the vicinity of category boundaries are enhanced, whereas those near the prototype or best exemplar of a phonetic category are reduced. More generally, prototypes serve to facilitate fast and accurate processing of linguistically relevant information.

The majority of Kuhl's perceptual magnet experiments (Grieser \& Kuhl, 1989; Iverson \& Kuhl, 1995; Kuhl, 1991; Kuhl, Williams, Lacerda, Stevens, \& Lindblom, 1992) have focused on vowel perception. These experiments employ synthetic stimulus sets in which 32 stimuli emanate from a prototypic or nonprototypic English / $\mathrm{i}$ / (based on average production data from Peterson \& Barney, 1952) in steps of $30,60,90$, and 120 mels to form eight vectors or four rings, each with eight stimuli, around the referent. Subjects participate in one of two conditions (prototype or nonprototype), in which they are presented with the referent paired with itself or one of it variants and indicate whether a change occurred. Typically, discrimination is poorer overall for the prototype than for the nonprototype condition-an effect sometimes deemed sufficient to indicate the operation of a magnet effect (Lively \& Pisoni, 1997; see also Aaltonen, Eerola, Hellstrom, Uusipaikka, \& Lang, 1997; Iverson \& Kuhl, 1995; Kuhl et al., 
1992). However, it is also the case that, although discrimination improves for variants that are further away from their referent, this effect is usually less marked for the prototype condition - that is, a condition $\times$ distance interaction obtains (see the studies described below). Thus, a stimulus that is only 30 mels from its referent is more difficult to discriminate in the prototype condition than in the nonprototype condition, and stimuli must be further from the prototype than the nonprototype in the vowel space for a change to be detected, even though the two stimulus sets are configured identically in psychoacoustic (mel) units (see, e.g., Kuhl, 1993b, p. 40). Such a pattern of results clearly provides the strongest support for the theoretical claim that phonetic prototypes exert a special pull on surrounding stimuli.

In a first study examining whether infants have prototypes for native vowels, Grieser and Kuhl (1989) compared 6-month-old infants' discrimination for prototypic and nonprototypic stimulus sets, using the visually reinforced headturning paradigm. Two groups of infants heard either an adult-defined prototype or a nonprototype /i/ (see above) as the background, repeating stimulus and were trained to make a headturn whenever they detected a change in this stimulus (i.e., when one of its variants was played instead). Infants in the prototype condition had significantly lower overall percent correct scores (hits or correct detections of a stimulus change, averaged together with correct rejections) and more misses than those in the nonprototype condition, and discrimination generally increased the further away the stimuli were from the referent. More important, a significant condition $\times$ distance interaction indicated that discrimination was poorer in the prototype than in the nonprototype condition, especially for the 30 - and 60 -mel stimuli. Furthermore, infants' percent correct scores were negatively correlated with adults' goodness ratings; that is, stimuli that adults had rated as good or prototypic exemplars of $/ i$ / were more difficult for infants to discriminate than stimuli rated as poor or nonprototypic exemplars (but see below regarding individual differences in such ratings).

Kuhl (1991) subsequently showed that, whereas both human adults and 6-month-old infants exhibit a magnet effect, Rhesus monkeys do not. Specifically, adults and infants had lower discrimination scores overall for the prototype condition than for the nonprototype condition, and a significant condition $\times$ distance interaction was again found, so that discrimination at 30 mels by adults and at 30 and 60 mels by infants was especially poor in the prototype condition. In contrast, monkeys displayed only the typical distance or stimulus generalization effect: "of main interest [neither] the effect of condition ... [nor] the condition $\times$ distance interaction ... was significant for the monkeys" (p. 103). Findings were interpreted as indicating that the magnet effect results from experience with spoken language, rather than being a general auditory phenomenon.
To assess how specific language experience contributes to the perceptual magnet effect, Kuhl et al. (1992) conducted a cross-linguistic study with 6-month-old American English and Swedish infants. The American infants tended to equate (failed to discriminate) the English vowel prototype / $\mathrm{i} /$ and its variants, whereas they evidenced better discrimination for a Swedish vowel prototype /y/ and its variants. Conversely, Swedish infants equated the Swedish prototype and its variants, but not the English one and its variants. This interaction between language background and vowel identity was used to argue that "by 6 months infants exhibit a strong magnet effect only for native-language phonetic prototypes ... [and] foreign-language prototypes have begun to function like nonprototypes in the native language" (p. 608). (Distance was not included as a factor in the analysis reported, but, as in previous studies, discrimination was apparently poorest for variants close to the referent vowel, especially the native/prototypic one.) More generally, Kuhl et al. maintain that a language-specific pattern of phonetic perception is in play by at least 6 months of age (prior to the emergence of contrastive phonology and an understanding of word meaning) and that early phonetic development thus proceeds, in part, by relatively passive exposure to the native language.

In these first studies of the magnet effect, adult subjects rated various exemplars of the vowel $/ i$ / for category goodness but were not given the opportunity to label the stimuli (but see Kuhl et al., 1992). Thus, it is unclear whether subjects perceived all of the stimuli as belonging to the same phonetic category-a necessary condition for the magnet effect. (Again, the central feature of this effect is that the discriminablility of stimuli within a given phonetic category varies inversely with category goodness.) If this condition was not met, subjects might actually have been performing a between-, rather than a within-category discrimination task. To address this problem, recent investigations of the magnet effect have administered identification tasks, in addition to goodness rating and discrimination tasks (Iverson \& Kuhl, 1995; Lively \& Pisoni, 1997; Sussman \& Lauckner-Morano, 1995). These investigations have revealed that subjects vary considerably in their identifications of $/ \mathrm{i} /$; Kuhl's (1991) nonprototype is not consistently labeled as $/ \mathrm{i} /$; and a more extreme $/ \mathrm{i}$ / with lower $F 1$ and higher $F 2$ values than Kuhl's prototype is sometimes selected as the best exemplar of $/ \mathrm{i} /$. In fact, Iverson and Kuhl (1995) found that the nonprototype received only $55 \%$ identification as /i/ across all their subjects; Sussman and Lauckner-Morano's (1995) subjects labeled this stimulus as / i / only $20 \%$ of the time; and Lively and Pisoni's subjects did so only $28 \%$ of the time. In addition, Iverson and Kuhl (1995) found that subjects chose (as indicated by goodness ratings) a stimulus 75 mels to the left of Kuhl's prototype as the best exemplar of /i/. Lively and Pisoni found that 21 of the 33 stimuli in Kuhl's prototype set were rated as "best" by at least 1 subject, thus demonstrating a lack of consensus 


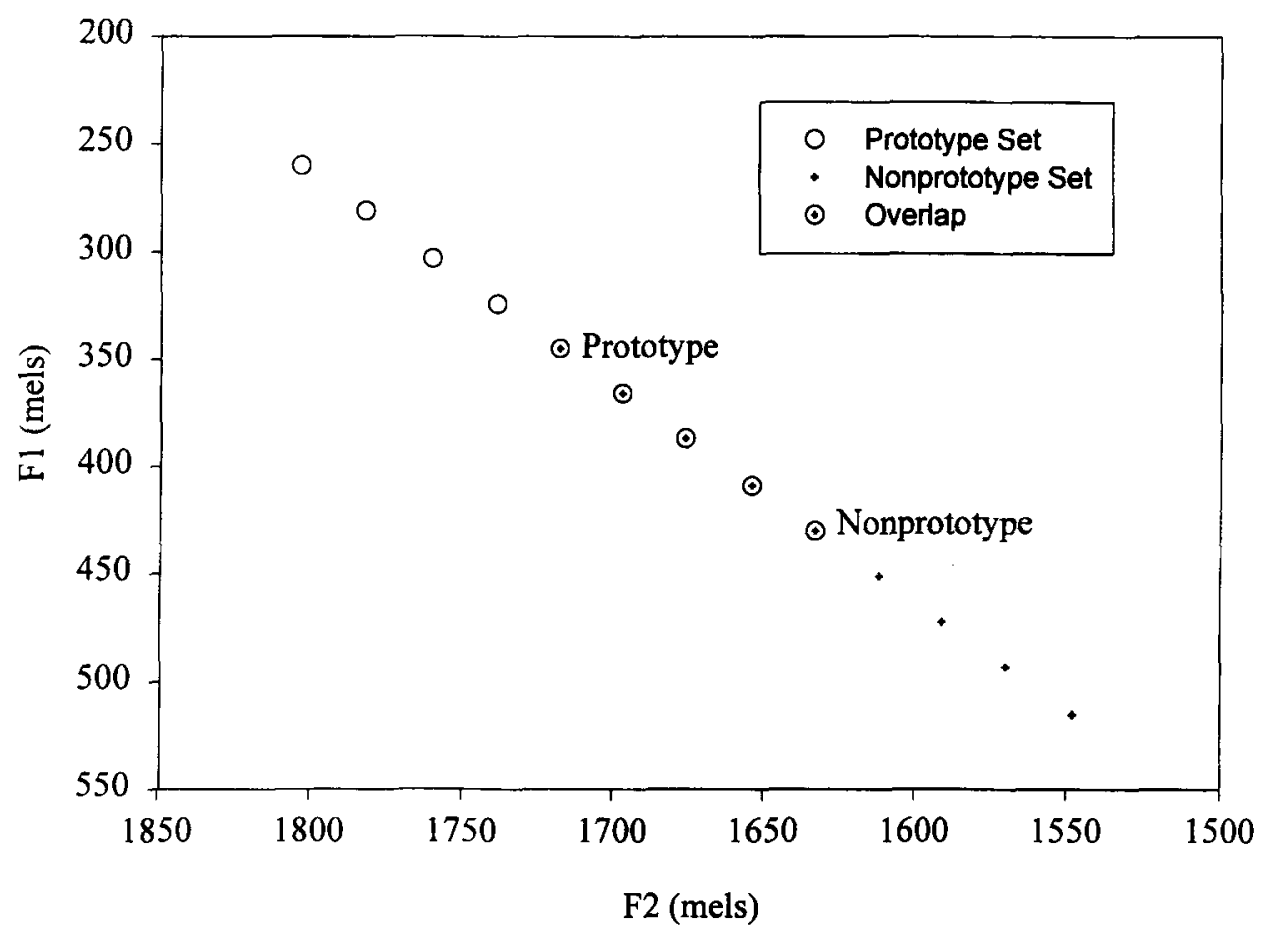

Figure 1. Stimulus sets in Iverson and Kuhl's (1995) identification and rating experiment.

regarding prototype location. In addition, subjects' goodness ratings were found to vary with stimulus context that is, Kuhl's prototype was given the highest rating overall when it was embedded in the nonprototype stimulus set, but lower ratings when embedded in the prototype stimulus set (see also Iverson \& Kuhl, 1995).

In their assessment of the magnet effect, Iverson and Kuhl (1995) employed a subset of Kuhl's (1991) stimuli that consisted of the original prototype, the nonprototype, and variants, all falling along a single, overlapping vector in the vowel space (see Figure 1; this figure and the others in our report are traditionally configured, with $F 1$ shown on the $y$-axis and $F 2$ on the $x$-axis). Results showed that discrimination, as indexed by $d^{\prime}$ (an unbiased measure of sensitivity), was worse overall for the prototype and the three variants to either side of it than it was for the nonprototype and its variants. Most important, discrimination was worse for stimuli to the left of the prototype (which had received the highest goodness ratings) than it was for stimuli to the right of the prototype (which had received lower goodness ratings); no such difference was found for stimuli to the left and the right of the nonprototype. These results serve to bolster Kuhl's claim regarding the existence of a perceptual magnet effect, inasmuch as discrimination was poorer within the / $\mathrm{i}$ / category than at the category boundary and poorest for the best category exemplars.

In their study, Sussman and Lauckner-Morano (1995) conducted multiple discrimination tasks with a subset of Kuhl's original stimuli that were configured as in the Iver- son and Kuhl (1995) study, but with a step size of 15 rather than 30 mels. (In addition, whereas the stimuli in Kuhl's, 1991, study were scaled according to a Euclidean metric, those in Sussman and Lauckner-Morano's study were not.) A more appropriate nonprototype (positioned $67 \mathrm{mels}$ from the prototype $/ \mathrm{i} /$ ), which received at least $50 \%$ identification as $/ i /$, was also employed. Subjects heard one of the following five stimuli as the fixed standard or referent stimulus: Kuhl's prototype, her nonprototype, a 75-up mel nonprototype with increasing $F 1$ and decreasing $F 2$ values (i.e., moving toward the nonprototype in the vowel space), a 75-down mel nonprototype with decreasing $F 1$ and increasing $F 2$ values (moving toward the prototype in the vowel space), or the 67-mel nonprototype with decreasing $F 1$ and increasing $F 2$ values. In accordance with the magnet effect, the prototype group displayed the poorest discrimination ( $d^{\prime}$ scores) overall, and this effect was especially pronounced for the 30 - and 45 mel stimuli, whereas the 75-down group displayed the best discrimination. (Apparently, however, the condition $\times$ distance interaction was not formally tested.) Sussman and Lauckner-Morano nevertheless argued that the 75-down group may have used the $F 1$ component as the most important acoustic cue for their judgments, because the subjects in this group had a fixed standard stimulus with a higher $F 1$ value than the comparison stimulus (see also Lively \& Pisoni, 1997, regarding the effects of $F 1$ and $F 2$ on discrimination). They further suggested that the higher discrimination scores of the 75-down group were attributable to increased auditory resolution-not to a phoneti- 
cally based magnet effect, because previous research has shown that there is better sensitivity to frequency comparisons going from high to low (Dooley \& Moore, 1988).

More recently, Lively and Pisoni (1997) conducted a discrimination experiment using a same-different paradigm (after Kuhl, 1991), with Kuhl's original prototype and nonprototype stimuli in one condition and prototype and nonprototype stimuli that were customized for individual subjects in another condition. The customized stimuli were chosen on the basis of goodness ratings, which indicated that many subjects had disparate prototypes. Although the standard distance effect was found in both conditions (as stimuli moved further away from the referent stimulus, discrimination or $d^{\prime}$ improved), discrimination did not differ overall for the prototype and nonprototype stimuli in either condition, and it was not especially poor for variants close to either type of prototype. Similar results were obtained for Kuhl's stimuli in another experiment employing a more sensitive (4IAX) discrimination paradigm. Thus, in this most recent study, little evidence for a magnet effect was observed.

In sum, recent research has shown that Kuhl's (1991) nonprototype / $/$ / may not be an appropriate stimulus for all subjects and stimulus sets in assessing the magnet effect (Iverson \& Kuhl, 1995; Lively \& Pisoni, 1997; Sussman \& Lauckner-Morano, 1995). In addition, although most previous work examining the magnet effect has assumed that speakers/listeners of English share the same /i/ prototype, the study by Lively and Pisoni, in particular, suggests that there may be no generic, "one-size-fits-all" prototype. Indeed, other research indicates that speakers differ considerably in their productions of this vowel (see Labov \& Ash, 1997) and that subjects employ even more disparate acoustic values in perceiving vowels and consonants than they do in producing them (Flege \& Schmidt, 1995; Johnson, Flemming, \& Wright, 1993; Samuel, 1982). Most important for our purposes, although we know that Kuhl's work was conducted in Washington, Sussman and Lauckner-Morano's in New York, and Lively and Pisoni's in Indiana with university students, little information is actually provided about the dialect background of these subjects (but see Kuhl, 1993b). Because it is likely that the dialect background of the subjects varied across these studies, and perhaps even within a given study, it cannot be assumed that they shared the same prototype (but see Lively \& Pisoni, 1997, Experiment 2).

We were interested in gaining additional information about possible individual differences in prototype selection and how such differences might impact on claims regarding the magnet effect. Therefore, speakers of diverse dialects of American English were explicitly chosen to participate in the present study. In Experiment 1, a preliminary identification test was conducted in order to roughly delimit the /i/ category in the $F 1 \times F 2$ vowel space for each subject. The subjects then listened to multiple exemplars of the vowel / $\mathrm{i}$ / and chose their own prototype, using a method-of-adjustment procedure. These data were, in turn, used to synthesize customized stimuli for Experiment 2, in which discrimination performance for prototypic and nonprototypic stimuli was assessed. Experiment 1 was completed to ensure that both the prototype and the nonprototype fell well within each subjects' / i/ category (see, also, Aaltonen et al., 1997).

In Experiment 2, a subset of those subjects who participated in Experiment 1 were tested, using a within-subjects roving discrimination task (see also Iverson \& Kuhl, 1995), which involved discrimination of pairs of stimuli in three regions of the vowel space: (1) near each subjects' /i / prototype, (2) near a nonprototypical / i/, and (3) near a foreign vowel not found in English (viz., Swedish $/ y /$ ). Each of these conditions employed a referent stimulus (prototype, nonprototype, or foreign) and four variants positioned $15,30,45$, and 60 mels away from the referent. Previous studies of the magnet effect have typically employed between-subjects designs (but see Iverson \& Kuhl, 1995); our within-subjects comparison should provide a more sensitive test of this effect. Another important aspect of this experiment was the inclusion of the foreign vowel condition. Although it has been suggested that foreign sounds function like nonprototypes in the native language (see, e.g., Kuhl et al., 1992), this claim has not actually been assessed before with adult subjects.

We focused, then, on evaluating three predictions regarding the relation between category goodness and discriminability that follow from NLM theory (Kuhl 1991, 1993a, 1993b, 1993c). First, if phonetic prototypes do indeed function as perceptual magnets, then, minimally, subjects should display poorer discrimination overall in the prototype condition than in the nonprototype condition. Second, we might expect to find that discrimination is especially poor for stimuli that are closest to the prototype rather than to the nonprototype. Such a condition $X$ distance interaction would provide even stronger support for the operation of a magnet effect (see, e.g., Grieser \& Kuhl, 1989; Kuhl, 1991). Third, discrimination should be poorer in the prototype than in the foreign condition, perhaps especially for stimuli close to the prototype, if foreign sounds function like nonprototypes from early infancy.

\section{EXPERIMENT 1}

Recent research suggests that the / $\mathrm{i}$ / prototype and nonprototype used by Kuhl (1991) may not have been appropriate for assessing the discrimination component of the magnet effect with all speakers/listeners of American English (Iverson \& Kuhl, 1995; Lively \& Pisoni, 1997; Sussman \& Lauckner-Morano, 1995). In the present experiment, a preliminary identification test was conducted to delimit each subject's / $i$ / category; then, each subject's / i / prototype was located, using a method-of-adjustment procedure. In this way, we were able to ensure that both the prototypic and the nonprototypic stimuli used in Experiment 2 fell within each subject's $/ \mathrm{i}$ / category and, thus, 
Table 1

Subjects' Dialect Background

\begin{tabular}{cl}
\hline Subject Number & City and State of Origin \\
\hline 1 & Longview, Texas \\
4 & Birmingham, Alabama \\
5 & Vadesta, Georgia \\
6 & Stone Mountain, Georgia \\
7 & Frederick, Maryland \\
9 & Birmingham, Alabama \\
10 & Seattle, Washington \\
13 & Evansville, Indiana \\
14 & Rochester, New York \\
15 & San Jose, California \\
16 & Fort Payne, Alabama \\
17 & Evansville, Indiana \\
18 & Detroit, Michigan \\
20 & Mobile, Alabama \\
21 & Portsmouth, Ohio \\
24 & Brooklyn, New York \\
26 & Revere, Massachusetts \\
28 & Birmingham, Alabama \\
29 & Stanford, California \\
33 & Huntsville, Alabama \\
34 & Birmingham, Alabama \\
36 & East Lansing, Michigan \\
37 & Midland, Texas \\
\hline
\end{tabular}

that subjects completed a within- rather than a betweencategory discrimination task.

\section{Method}

\section{Subjects}

Thirty-seven phonetically untrained, monolingual, male subjects were recruited from the undergraduate and graduate student populations of the University of Alabama at Birmingham and were paid for their participation. ${ }^{1}$ The subjects were from various parts of the United States and had resided most of their lives (minimally, the first 15 years of childhood) in the cities and states listed in Table 1 (this information is shown only for those 24 subjects who completed the entire study). All had normal speech, and their hearing was screened at $20 \mathrm{~dB}$ for the octaves of $250-8000 \mathrm{~Hz}$.

\section{Stimuli}

The parameters used for stimulus synthesis were based on the results of a pilot experiment, in which the first and second formants varied orthogonally ( $F 1$ in 11 steps from 150 to $450 \mathrm{~Hz}, F 2$ in 19 steps from 1060 to $2500 \mathrm{~Hz}$ ). Five pilot subjects (also representing diverse dialects) listened to the full range of stimuli (via Sennheiser HD 490 headphones) and labeled each with one of six key words provided on a computer keyboard. The keywords were bait, bet, beet, boot, but, and bit; a choice of other was also available, because some of the vowel stimuli do not occur in English. The stimuli with $F \mathbf{l}$ and $F 2$ values of more than 420 and $1380 \mathrm{~Hz}$, respectively, were rarely labeled as $/ \mathrm{i} /$; therefore, these parameters were deemed appropriate for defining the range of possible / $\mathrm{i} /$ sounds in Experiment 1 .

The stimuli were constructed with a Klatt (1980) formant synthesizer. A grid of vowels was formed such that $F 1$ and $F 2$ varied orthogonally in roughly just noticeable differences (Fant, 1973). F1 varied in 15 steps of approximately $20 \mathrm{~Hz}$, ranging from 150 to $430 \mathrm{~Hz} ; F 2$ varied in 22 steps of approximately $53 \mathrm{~Hz}$, ranging from 1380 to $2500 \mathrm{~Hz}$, to yield a total of 330 vowel stimuli (see Table 2, which also shows mel values). All other parameters were held constant, with $F 3=3010 \mathrm{~Hz}, F 4=3300 \mathrm{~Hz}, F 5=3850 \mathrm{~Hz}$ and bandwidths set at $B 1=53, B 2=77, B 3=111, B 4=175$, and $B 5=281$.
The fundamental frequency $(F 0)$ began at $112 \mathrm{~Hz}$, rose to $132 \mathrm{~Hz}$ over the first $100 \mathrm{msec}$, and dropped to $92 \mathrm{~Hz}$ over the remainder of each stimulus, which was $435 \mathrm{msec}$ long. Stimuli were root-mean square normalized to equalize for loudness and ramped at $20 \mathrm{msec}$ at both the beginning and the end of the signal, to prevent clicks.

\section{Procedure}

In the preliminary identification test, the subjects were randomly presented with the 330 vowels from the fine-grained stimulus set described above (cf. Aaltonen et al., 1997; Lively \& Pisoni, 1997). The stimuli were presented in individual test sessions via a personal computer over headphones in a sound-treated room. The subjects had to identify each stimulus as either "ee" (/i/) or "not ee" by pressing one of two labeled buttons. This identification test served two important purposes: First, the subjects were familiarized with the synthetic stimulus set; second, it allowed us to obtain a rough estimate of each subject's / i / category, including its outer limits.

The main experimental task, which utilized a method-ofadjustment procedure to locate individual subjects' /i/ prototype (P), was administered next. The subjects were presented with a twodimensional grid consisting of 330 boxes on a computer screen, each box specifying a different vowel stimulus with a unique $F 1 \times F 2$ frequency combination. Each subject was tested individually and instructed to locate the vowel within the grid that represented the best exemplar of the vowel $/ \mathrm{i} /$, as in the keyword $h e$. The subjects were able to move about the grid, using a mouse, and clicking on each box caused a different vowel token to be played out over their headphones.

The subjects received 2 practice trials to familiarize them with the experimental task. After practice, there were two blocks of 15 trials, with a break in between, for a total of 30 trials. The orientation of the grid changed randomly from trial to trial by a rotation of the $F 1$ and $F 2$ axes, to ensure that the subjects would not rely solely on the visual orientation of the grid in making their selections.

At the beginning of each trial, four corner vowels were played, to orient subjects within the grid. The boxes corresponding to these corner stimuli were briefly illuminated as each stimulus was played. During the course of each trial, the subjects could determine which of the stimuli they had heard, because the squares of the grid dark-

Table 2

$F 1$ and $F 2$ Values for Stimuli in Experiment 1 ( $\mathrm{Hz}$ and Mels)

\begin{tabular}{cccc}
\hline$F 1(\mathrm{~Hz})$ & $F 1(\mathrm{Mels})$ & $F 2(\mathrm{~Hz})$ & $F 2(\mathrm{Mels})$ \\
\hline 150 & 202 & 1380 & 1251 \\
168 & 224 & 1424 & 1277 \\
186 & 246 & 1469 & 1304 \\
205 & 269 & 1515 & 1331 \\
224 & 292 & 1562 & 1357 \\
243 & 314 & 1609 & 1384 \\
263 & 337 & 1657 & 1410 \\
283 & 360 & 1707 & 1437 \\
303 & 382 & 1757 & 1463 \\
323 & 404 & 1808 & 1490 \\
344 & 427 & 1860 & 1516 \\
365 & 449 & 1913 & 1543 \\
387 & 472 & 1967 & 1569 \\
408 & 494 & 2022 & 1596 \\
430 & 516 & 2078 & 1622 \\
& & 2135 & 1648 \\
& & 2193 & 1675 \\
& & 2252 & 1701 \\
& & 2313 & 1728 \\
& & 2374 & 1754 \\
& & 2437 & 1781 \\
& & 2500 & 1807 \\
\hline
\end{tabular}

Note-Each $F 1$ value was paired with each $F 2$ value once, for a total of 330 stimuli. 


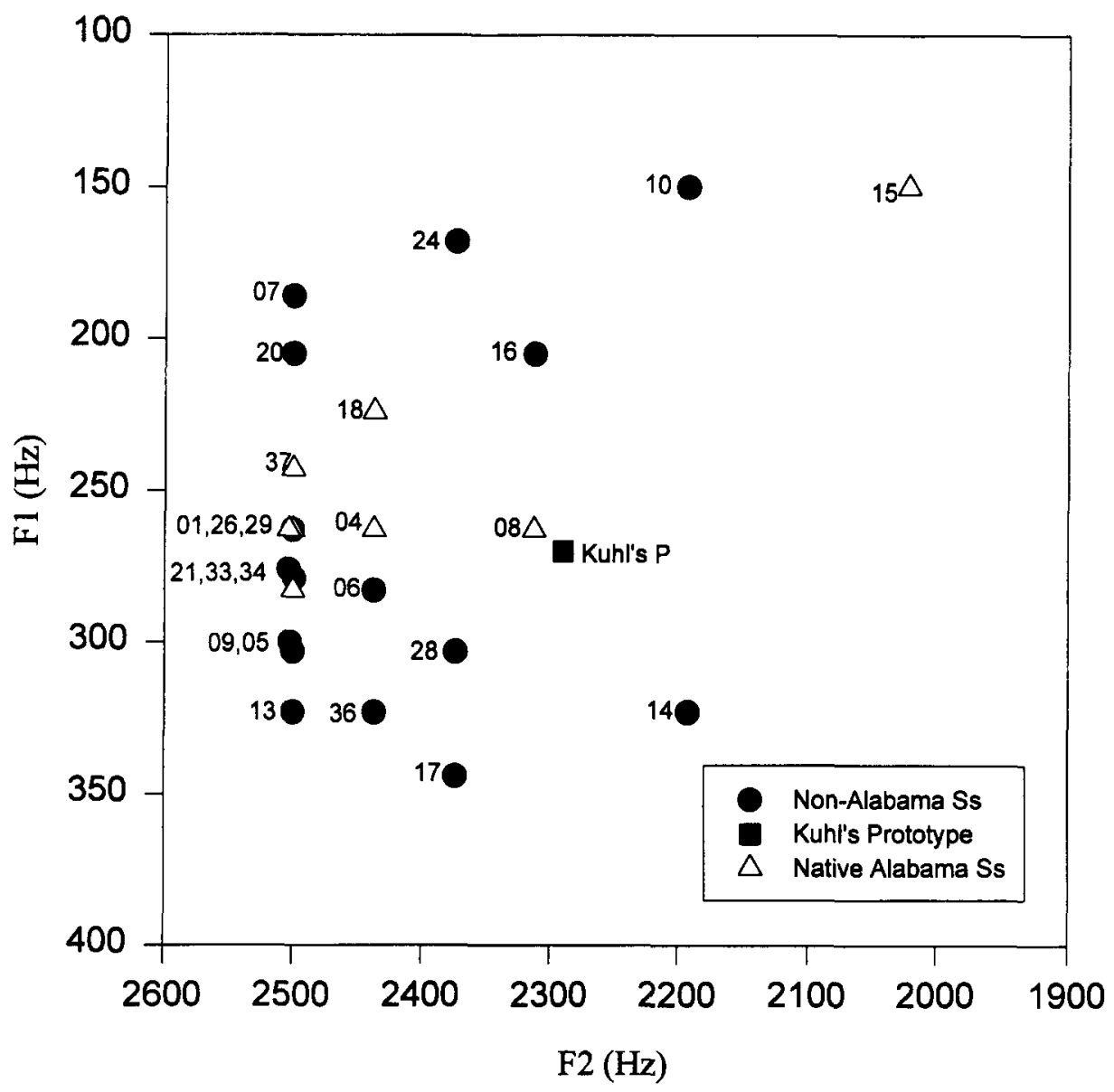

Figure 2. Individual subjects' prototype selections in Experiment 1 as a function of dialect background. Also shown is Kuhl's (1991) prototype. Numbers represent subject numbers (see Table 1).

ened cumulatively with each click. (A box became completely black on the 20th click.) All the squares in the grid were cleared at the beginning of each trial. After the subjects listened to as many stimuli as they judged necessary to find the best exemplar of $/ \mathrm{i} /$, they selected that particular stimulus by clicking a box that read "I like that one best." Their responses were recorded by the computer, and the next trial was initiated. After the subjects completed both blocks of 15 trials, they rated each of their selected stimuli on a 10-point Likert scale $(1=$ terrible and $10=$ excellent $)$ for category goodness.

Criteria for prototype selection. Only those subjects who were consistent in their selection of a $\mathrm{P}$ were included in the discrimination task (Experiment 2). Specifically, the most frequently selected stimulus (the mode) was designated as the $P$, with the restriction that a subject had to choose 1 of the 330 vowel stimuli as "best" on at least $4(13 \%)$ or more of the 30 trials (see also the Results section). (This minimum criterion was used because, apart from subjects who selected a stimulus only 1-2 times, it was the mode across different subjects.) In cases in which more than one stimulus was selected an equal number of times, the stimulus that received the highest goodness rating was defined as the P. These competing Ps had to be adjacent in either the $F 1$ or the $F 2$ dimension.

\section{Results}

Twenty-four of our 37 original subjects met the criteria for prototype selection described earlier. In general, our subjects'/i / prototypes were more extreme or higher in the $F 1$ and $F 2$ dimensions than the stimulus used by Kuhl (1991), as is shown in Figure 2 (see also Iverson \& Kuhl, 1995; Lively \& Pisoni, 1997; Sussman \& LaucknerMorano, 1995). Furthermore, although most of our subjects' prototypes were clustered in a similar area of the vowel space, 16 of these 24 subjects selected disparate and unique prototypes with a few extreme outliers. There was, then, a lack of consensus in selecting a prototype, even among subjects from the same state (i.e., Alabama). Thus, there appears to be more variation in prototype selection than has been recognized in the past (but see Aaltonen et al., 1997; Lively \& Pisoni, 1997).

In designating a prototype for each subject, we might have used either the mode (i.e., the stimulus most frequently selected as "best" on 30 trials) or the mean (i.e., averaged $F 1$ and $F 2$ values for the various stimuli selected as "best" on these trials). We chose the former over the latter, largely because subjects actually heard, selected, and rated the modal stimulus, whereas choosing the mean would have involved synthesizing a novel stimulus from averaged data. However, as one can see in Table 3, the $F 1$ and $F 2$ values associated with the mode and mean were very similar in most cases. In fact, a paired difference $t$ test comparing the modal with the mean $F 1$ values was not sig- 
Table 3

$F 1$ and $F 2$ Values (in Hertz) for Each Subject's Modal Stimulus, Mean (With Standard Deviation), and Confidence Interval for the Mean

\begin{tabular}{|c|c|c|c|c|c|c|c|c|c|c|c|}
\hline \multirow{3}{*}{$\begin{array}{l}\text { Subject } \\
\text { Number }\end{array}$} & \multirow{3}{*}{$\begin{array}{c}\text { Mode } \\
\text { (No. of Trials) }\end{array}$} & \multicolumn{5}{|c|}{$F 1$} & \multicolumn{5}{|c|}{$F 2$} \\
\hline & & \multirow[b]{2}{*}{ Mode } & \multicolumn{2}{|c|}{ Mean } & \multirow{2}{*}{$\begin{array}{c}\text { Confidence } \\
\text { Interval }\end{array}$} & \multirow{2}{*}{$\stackrel{\Delta}{M M}$} & \multirow[b]{2}{*}{ Mode } & \multicolumn{2}{|c|}{ Mean } & \multirow{2}{*}{$\begin{array}{c}\text { Confidence } \\
\text { Interval }\end{array}$} & \multirow{2}{*}{$\begin{array}{c}\Delta \\
M M\end{array}$} \\
\hline & & & $M$ & $S D$ & & & & $M$ & $S D$ & & \\
\hline 1 & 10 & 263 & 262 & 25.0 & $253-271$ & 0 & 2500 & 2481 & 52.0 & $2462-2500$ & 0 \\
\hline 4 & 11 & 263 & 276 & 17.0 & $270-282$ & -7 & 2437 & 2435 & 20.0 & $2428-2442$ & 0 \\
\hline 5 & 9 & 303 & 294 & 21.0 & $287-302$ & 1 & 2500 & 2424 & 170.0 & $2363-2485$ & 15 \\
\hline 6 & 4 & 283 & 268 & 25.0 & $257-277$ & 6 & 2437 & 2400 & 70.5 & $2375-2425$ & 12 \\
\hline 7 & 4 & 186 & 186 & 27.0 & $176-196$ & 0 & 2500 & 2430 & 117.5 & $2388-2472$ & 28 \\
\hline 8 & 7 & 263 & 254 & 15.3 & $249-259$ & 4 & 2313 & 2274 & 111.0 & $2234-2314$ & 0 \\
\hline 9 & 5 & 303 & 288 & 24.6 & $279-297$ & 6 & 2500 & 2423 & 77.7 & $2395-2451$ & 49 \\
\hline 10 & 6 & 150 & 157 & 10.1 & $153-161$ & -3 & 2193 & 2235 & 129.4 & $2189-2281$ & 0 \\
\hline 13 & 7 & 323 & 308 & 28.8 & $298-318$ & 5 & 2500 & 2444 & 67.8 & $2420-2468$ & 32 \\
\hline 14 & 4 & 323 & 310 & 19.3 & $303-317$ & 6 & 2193 & 2333 & 163.6 & $2274-2392$ & -81 \\
\hline 15 & 5 & 150 & 156 & 25.0 & $147-165$ & 0 & 2022 & 2119 & 211.1 & $2043-2195$ & -21 \\
\hline 16 & 6 & 205 & 219 & 11.1 & $215-223$ & -10 & 2313 & 2258 & 93.6 & $2225-2291$ & 22 \\
\hline 17 & 4 & 344 & 334 & 17.1 & $328-340$ & 4 & 2374 & 2321 & 130.1 & $2274-2368$ & 8 \\
\hline 18 & 4 & 224 & 245 & 40.5 & $230-260$ & -6 & 2437 & 2441 & 56.7 & $2121-2461$ & 0 \\
\hline 20 & 4 & 205 & 228 & 38.3 & $214-242$ & -9 & 2500 & 2373 & 146.3 & $2321-2425$ & 75 \\
\hline 21 & 8 & 283 & 289 & 18.3 & $282-296$ & 0 & 2500 & 2454 & 69.2 & $2429-2479$ & 21 \\
\hline 24 & 7 & 168 & 176 & 24.2 & $167-185$ & 0 & 2374 & 2330 & 110.7 & 2294-2366 & 8 \\
\hline 26 & 8 & 263 & 261 & 34.2 & $249-273$ & 0 & 2500 & 2471 & 39.6 & $2457-2485$ & 15 \\
\hline 28 & 7 & 303 & 286 & 25.4 & $277-295$ & 8 & 2374 & 2311 & 68.1 & $2287-2335$ & 39 \\
\hline 29 & 7 & 263 & 264 & 38.3 & $250-278$ & 0 & 2500 & 2465 & 78.6 & $2437-2493$ & 7 \\
\hline 33 & 4 & 283 & 251 & 37.9 & $237-265$ & 18 & 2500 & 2438 & 85.9 & $2407-2469$ & 31 \\
\hline 34 & 6 & 283 & 282 & 16.2 & $276-288$ & 0 & 2500 & 2485 & 31.8 & $2474-2496$ & 4 \\
\hline 36 & 4 & 323 & 297 & 43.2 & $282-312$ & 11 & 2437 & 2398 & 95.4 & $2364-2432$ & 5 \\
\hline 37 & 7 & 243 & 255 & 24.4 & $246-264$ & -3 & 2500 & 2427 & 86.5 & $2396-2458$ & 42 \\
\hline$M$ & & 258.3 & 256.1 & & & 4.5 & 2413.7 & 2382.1 & & & 21.46 \\
\hline$S D$ & & 56.1 & 47.8 & & & 4.6 & 126.4 & 91.8 & & & 22.62 \\
\hline
\end{tabular}

Note-The second column from the left shows the number of times the modal stimulus (prototype) was selected as "best" on 30 trials. $\triangle M M$ is the difference between the mode and the upper or lower limit of the confidence interval for the mean.

nificant $[t(23)=0.78, p>.05$, mean difference $=2.25 \mathrm{~Hz}$, $S D=14.21 \mathrm{~Hz}]$. A similar $t$ test for $F 2$ values was statistically significant $[t(23)=2.58, p<.05$, mean difference $=30.59 \mathrm{~Hz}, S D=63.76 \mathrm{~Hz}]$, but phenomenologically, it is likely that the differences involved are minimal (see below).

Table 3 also shows $95 \%$ confidence intervals that were constructed around the mean obtained for each subject. As one can see, the prototype (modal stimulus) for most subjects falls close to, if not actually in, the corresponding confidence interval: For $F 1$, the average difference between the mode and the upper or lower limit of the confidence interval was only $4.46 \mathrm{~Hz}(S D=4.58)$; for $F 2$, the average difference was $21.46 \mathrm{~Hz}(S D=22.62)$. Finally, to verify (at least indirectly) the reliability with which the prototype was selected, we calculated the average standard deviation in $F 1$ values for subjects' means, which was $25.3(S D=9.33)$ and significantly less than $30 \mathrm{~Hz}$, or a just noticeable difference for $F 1$ (Flanagan, 1955), according to a $t$ test $[t(23)=2.47, p<.05]$. The average standard deviation in $F 2$ values was $94.74(S D=46.21)$, which did not differ significantly from $80 \mathrm{~Hz}$, or a just noticeable difference for $F 2[t(23)=1.56, p>.05]$.

Table 4 provides a summary of the identification data for the 24 subjects with prototypes. As one can see, there is some consensus as to which stimuli belong to the $/ \mathrm{i}$ / category. However, it is also clear that there is less agreement regarding the identity of outlying stimuli-that is, as $F 1$ increases and $F 2$ decreases. Put another way, there is considerable variation among subjects regarding the location of the category boundary. Also shown in the table are the locations of our 24 subjects' prototypes within the / $i$ / vowel space as defined by the group. Comparable tables were constructed for each subject in order to obtain a rough estimate of the parameters needed to delimit that subject's / $i$ / category. Although the subjects were presented with each of the 330 stimuli represented in the table only once, the stimuli did comprise a very fine grained vowel grid in which the differences between adjacent stimuli were based on just noticeable differences (cf. Aaltonen et al., 1997; Lively \& Pisoni, 1997). Thus, our preliminary identification test provided a status check on the location of each subject's category boundary - an approach that we judged preferable to using data from any previous study or to employing averaged identification data from all of our subjects.

\section{EXPERIMENT 2}

The purpose of this experiment was to determine whether there is indeed reduced discriminability of vowels located near a listener's prototype for $/ \mathrm{i} /$, in comparison 


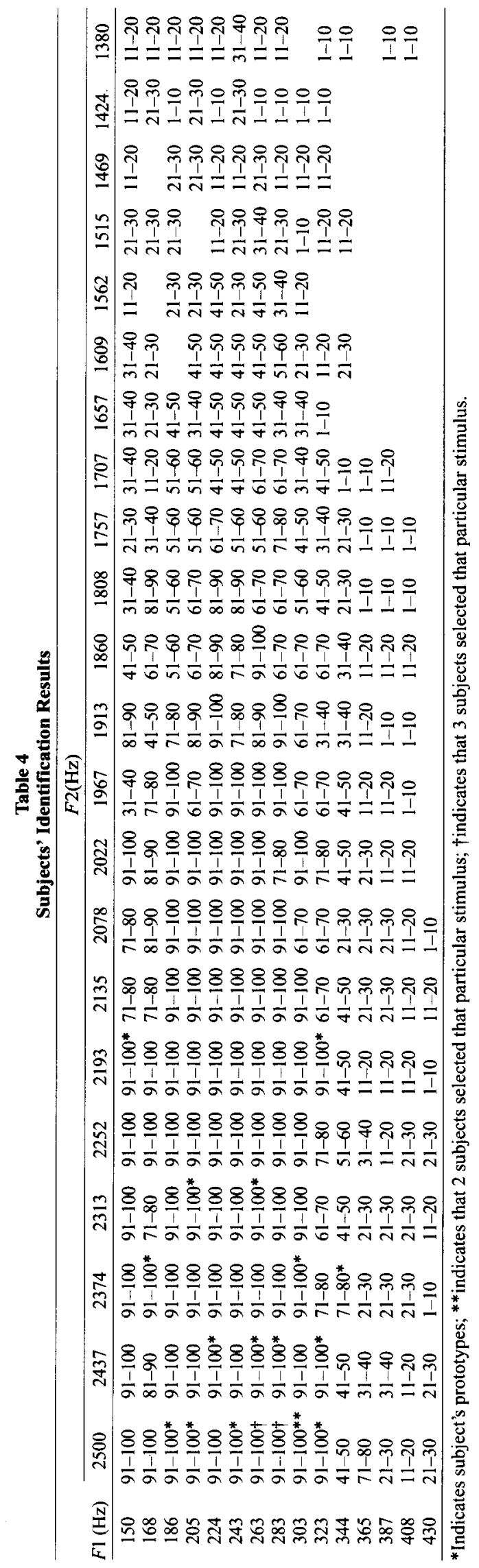




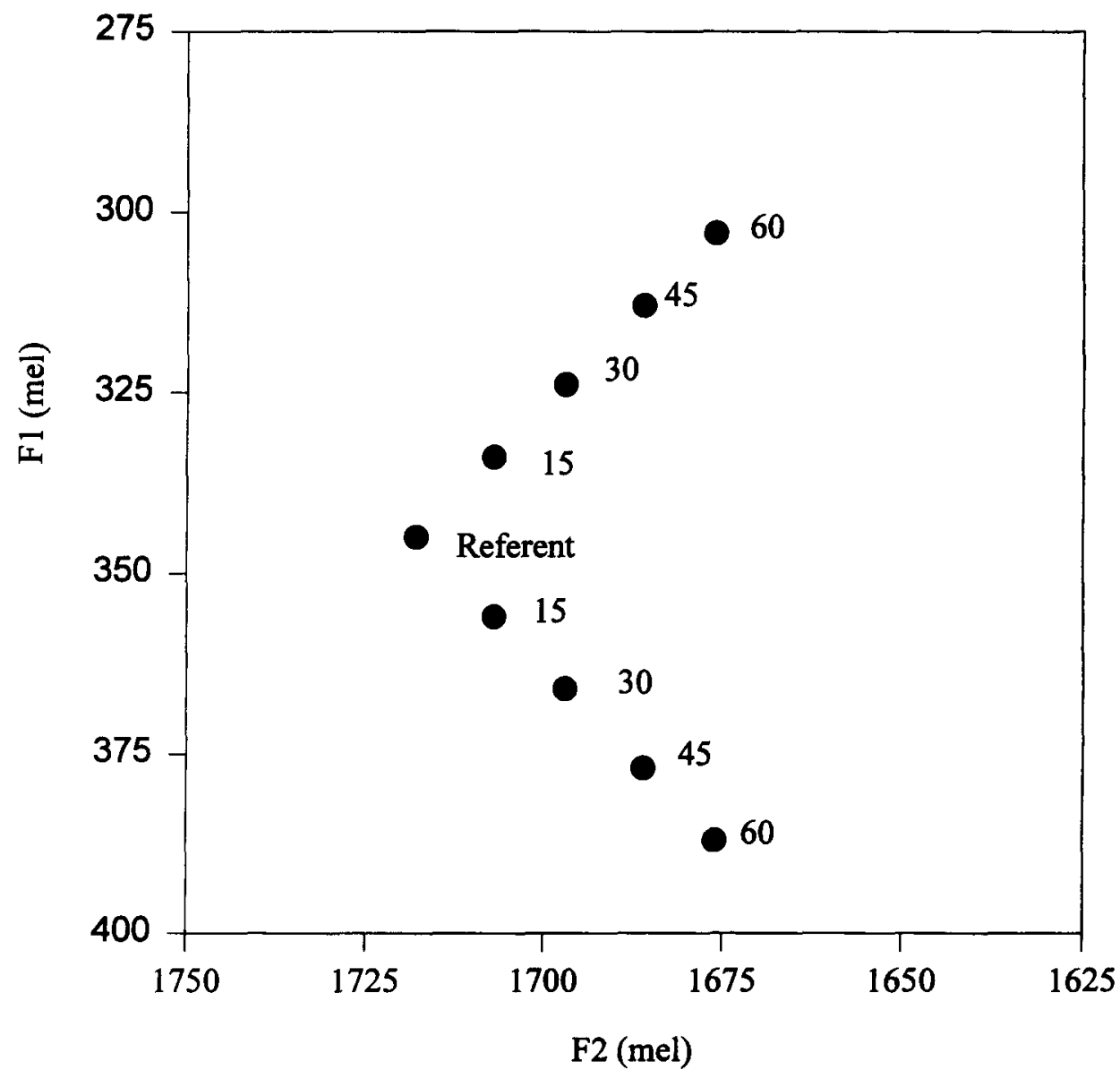

Figure 3. Configuration of stimuli in Experiment 2. The particular $F 1$ and $F 2$ values shown are illustrative only (see text regarding customization of stimulus sets).

with those near a nonprototypic stimulus-either a native but nonprototypic / $i$ / or a foreign, Swedish vowel / $y$ /. The subjects from Experiment 1 were tested in a withinsubjects version of the roving discrimination paradigm employed by Iverson and Kuhl (1995).

\section{Method}

\section{Subjects}

The 24 subjects who met our criteria for prototype (P) selection in Experiment 1 participated in Experiment 2 two weeks later.

\section{Stimuli}

There were five stimuli in each of three stimulus conditions. The stimuli in each condition consisted of a referent stimulus $(\mathrm{P}=$ prototype, NP = nonprototype, or F = foreign) and four additional stimuli that were equally spaced, according to a Euclidean metric, to form a straight line or vector in the $F 1 \times F 2$ vowel space. Following Sussman and Lauckner-Morano (1995), a step size of 15 mels was used to maximize sensitivity to differences in discrimination predicted by the magnet effect (cf. Grieser \& Kuhl, 1989; Iverson \& Kuhl, 1995; Kuhl, 1991; Kuhl et al., 1992). Thus, the four vector stimuli in each condition were $15,30,45$, and 60 mels away from the referent. The subjects were assigned to one of two groups, which are shown schematically in Figure 3: for Group 1 (Up), the vector stimuli had decreasing $F 1$ values and decreasing $F 2$ values; for
Group 2 (Down), the vector stimuli had increasing $F 1$ values and decreasing $F 2$ values. Group assignment was determined by the results of Experiment 1; if a subject's $P$ and NP fell on the periphery of his / i / category, the trajectory of the vector was positioned so that the 15-, 30-, 45-, and 60-mel stimuli fell within his / i/ category.

For the $\mathrm{P}$ and NP conditions, $F 3, F 4$, and $F 5$ were held constant across stimuli at 3010,3300 , and $3850 \mathrm{~Hz}$, respectively. For the $\mathrm{F}$ condition, formant frequencies were set at values appropriate for the Swedish vowel $/ \mathrm{y} /: F 1=220 \mathrm{~Hz}, F 2=1979 \mathrm{~Hz}, F 3=2640 \mathrm{~Hz}$, $F 4=3341 \mathrm{~Hz}$, and $F 5=3721 \mathrm{~Hz}$ (see Kuhl et al., 1992). Bandwidths were held constant across the three stimulus sets, with $B 1=$ $53 \mathrm{~Hz}, B 2=77 \mathrm{~Hz}, B 3=111 \mathrm{~Hz}, B 4=175 \mathrm{~Hz}$, and $B 5=281 \mathrm{~Hz}$. All other stimulus parameters were the same as those in Experiment 1 .

\section{Conditions}

Prototype. Each subject's / $/ \mathrm{P}$ was chosen on the basis of the results of Experiment 1.

Nonprototype. For all the subjects, the NP was posterior in the vowel space relative to $P$ (Ladefoged, 1962). The NP was positioned 120 mels from the $\mathrm{P}$, or back in the $F 1 \times F 2$ vowel space (i.e., the frequency of $F 1$ remained the same, but $F 2$ decreased). As is shown in the example of Figure 4, the P and NP were plotted for each subject, using the results of Experiment 1, including the preliminary identification data, to ensure that both referents and their variants fell within the subject's / $/$ / category. 


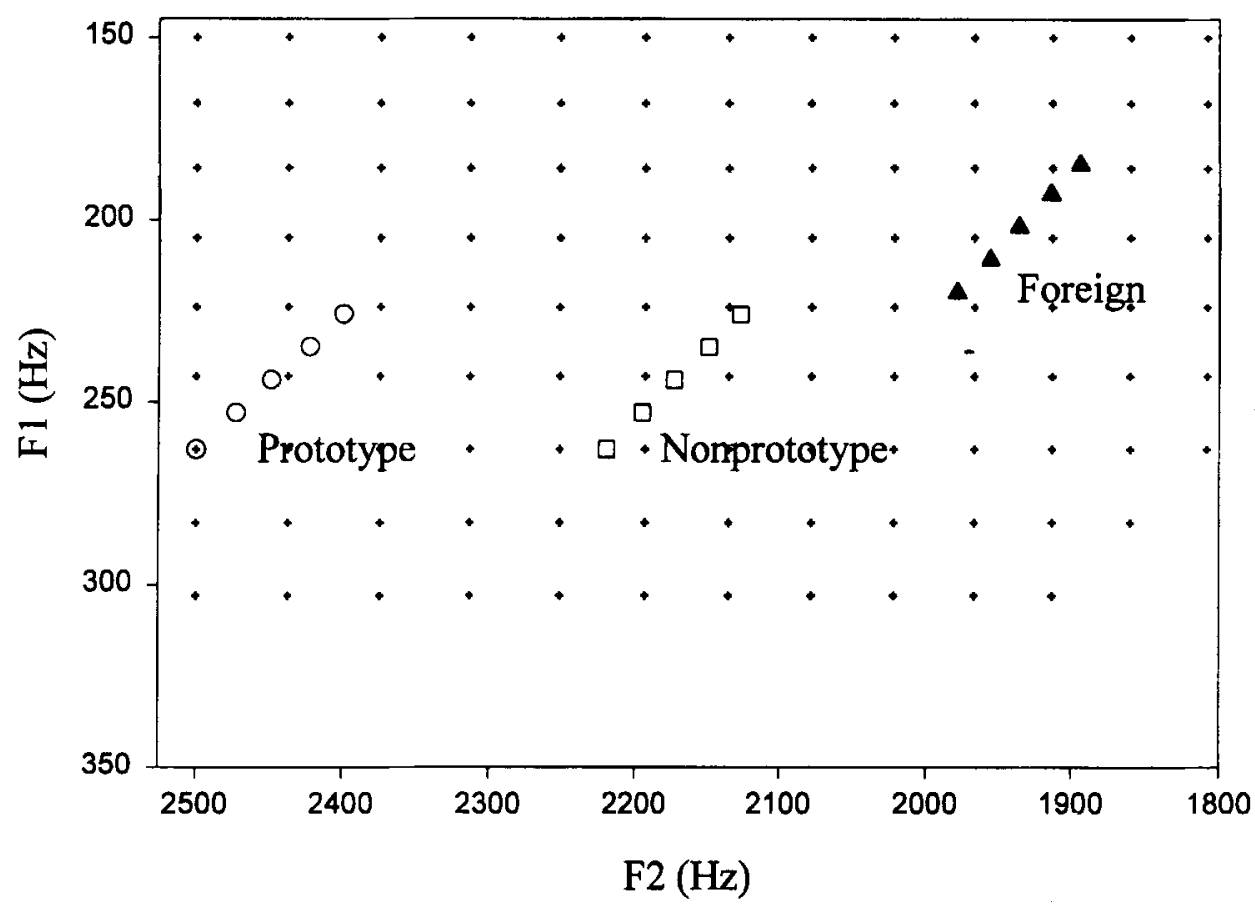

Figure 4. Illustration of Subject 1 's / $/$ / category, including prototype, nonprototype, and variant stimuli. The foreign referent and its variants are also shown (see the text regarding differing $F 3, F 4$, and $F 5$ values).

Foreign. The F (Swedish)/y/ stimuli were synthesized from the values specified by Kuhl et al. (1992). The four vector stimuli juxtaposed to the $F$ referent had the same configuration as in the $P$ and NP conditions (see Figures 3 and 4). Unlike the $P$ and NP referents, the $F$ referent was not customized for each subject, because our subjects were not expected to have a $P$ for this vowel.

\section{Procedure}

Given that our 24 subjects returned 2 weeks after completing Experiment 1 , we conducted a preliminary paired comparison task, to ensure that they preferred their $P$ over the NP and $F$ referents. Also, the NP was a novel stimulus for our subjects (as was the F referent), because it was synthesized on the basis of the results of Experiment 1 . The three referents were paired, using all possible combinations, for a total of 48 pairs ( $P$ and NP were paired 16 times, as were $P$ and $F$ and NP and F), and the subjects chose the best exemplar of / i / from each pair. A percent preference score was then calculated for each subject on the basis of the number of times $P$ was selected over the NP stimulus. (Subjects rarely, if ever, selected the F over the P or the NP.) Group 1 (Up) and Group 2 (Down) did not differ significantly in their preference scores $[M=76 \%$ and $81 \%$, $S D=17 \%$ and $25 \% ; t(11)=2.17, p>.21$; see Table 5 in the Results section]. In general, the subjects were fairly consistent in selecting their P: Twelve of 24 subjects had a preference score of $88 \%$ or greater, and 18 had a preference score of $75 \%$, whereas only 6 did not. The latter included Subject 4 , who actually selected the NP more often than his $P$. This reversal was perhaps an artifact of having completed the experiment twice (because of a computer failure). His data were, nevertheless, retained for analysis (but see note 2 in the Results section).

Each subject then participated in the main discrimination task for the three stimulus conditions described previously. Order of conditions was specified by a simple Latin square (i.e., the subjects were assigned to one of the following orders: $\mathrm{P}-\mathrm{NP}-\mathrm{F}, \mathrm{NP}-\mathrm{F}-\mathrm{P}$, or F-P-NP).
The discrimination task for each condition began with 48 practice trials, which were not analyzed. For practice, there was a ratio of $1: 2$ same/different trials. In testing, the same ratio was used; specifically, each condition had a total of 180 test trials composed of 60 same and 120 different trials. Twenty of the same trials consisted of two repetitions of the referent ( $\mathrm{P}, \mathrm{NP}$, or $\mathrm{F}$ ) paired with itself. The remaining 40 same trials consisted of the four vector stimuli paired with themselves 10 times. The 120 different trials consisted of the four vector stimuli paired with the referent 30 times each.

Each trial consisted of two vowel stimuli that were separated by an interstimulus interval of $500 \mathrm{msec}$. The subjects were instructed to listen carefully to each stimulus and to indicate whether the pair of stimuli was the same or different by pressing one of two buttons labeled accordingly. After the subjects responded, there was a 1-sec delay before the next pair was presented. For half of the different trials, the referent stimulus occurred in the first temporal position; the other half had one of the four vector stimuli in the first position. The subjects were given feedback for both practice and test trials via the illumination of a yellow light over the correct button.

\section{Data Analysis}

The primary dependent measure that we employed was $d^{\prime}$-an unbiased measure of sensitivity. A separate $d^{\prime}$ score, based on each subject's hits and false alarms, was calculated for each of the four vector stimuli $(15,30,45$, and $60 \mathrm{mels})$ in the three conditions, for a total of 12 scores (Macmillan \& Creelman, 1991). A hit (H) was defined as an instance in which the two stimuli in a pair were different and subjects correctly responded different. $\mathrm{H}$ rates were tallied for each of the four vector stimuli, with a maximum number of 30 hits possible for a stimulus. A false alarm (FA) was defined as an instance in which the two stimuli in a pair were the same, but subjects erroneously responded different. FA rates were calculated for each of the four vector stimuli for each condition in the following manner: (average FA for same trials with referent stimulus) + (average FA for each vector stimulus paired with itself)/2 (P. Iverson, 


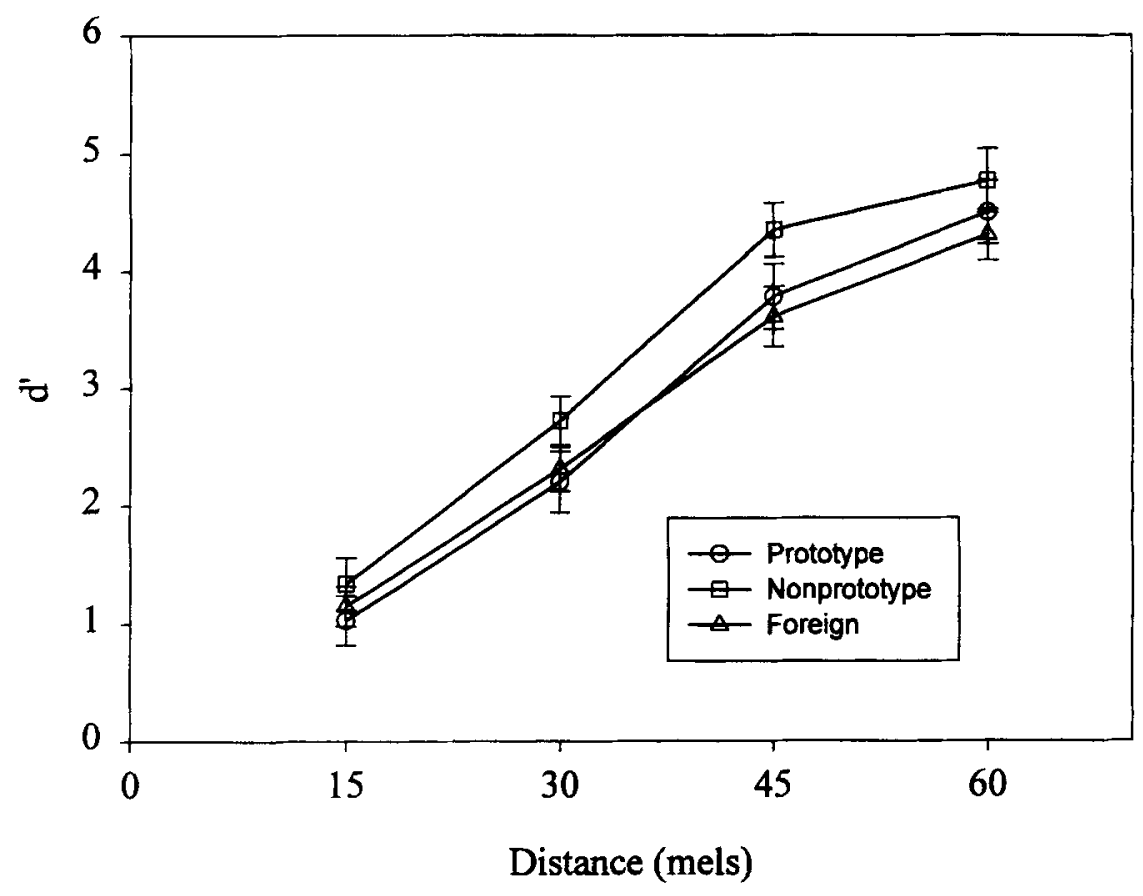

Figure 5. Mean $d^{\prime}$ scores (and standard errors) as a function of condition and distance in Experiment 2.

personal communication, March 28, 1995). When FA rates exceeded $\mathrm{H}$ rates, the two parameters were inverted, and a negative $d^{\prime}$ was calculated. Negative $d^{\prime}$ scores accounted for less than $5 \%$ of the discrimination data across the 24 subjects.

\section{Group Performance}

A group (Up or Down) $\times$ condition (prototype, nonprototype, foreign $) \times$ distance $(15,30,45$, or 60 mels $)$ analysis of variance (ANOVA) for subjects' $d^{\prime}$ scores yielded a significant main effect of condition $[F(2,44)=4.36, p<$ $.02]$. Tukey's post hoc tests $(p<.05)$ revealed that discrimination for the nonprototype condition $(M=3.29$, $S D=1.77$ ) was significantly greater than that for the prototype condition $(M=2.88, S D=1.83)$ and that for the foreign condition $(M=2.85, S D=1.59)$; performance for the prototype and foreign conditions did not differ (see Figure 5). The analysis also revealed a significant main effect of distance $[F(3,66)=222.45, p<.0001]$. That is, as stimuli moved further away in the vowel space from the referent stimulus, discrimination improved substantially in all three conditions. For the 15-, 30-, 45-, and 60-mel stimuli, the mean $d^{\prime}$ scores were $1.18,2.41,3.91$, and 4.53 ( $S D$ s, $0.97,1.09,1.27$, and 1.25), respectively; each adjacent comparison was significant, according to post hoc tests. ${ }^{2}$

No other effects were significant in this analysis. Most important for present purposes, the condition $\times$ distance interaction failed to reach significance $[F(6,132)=0.92$, $p>.05]$. Our failure to observe this interaction might be attributed to a lack of statistical power, which is a func- tion of four parameters: significance level, number of study participants, precision of data collection and data analysis, and effect size. In the present experiment, we employed the standard alpha level of .05 for rejecting the null hypothesis. The number of subjects was also appropriate for a three-factor mixed design (10-15 subjects per group is common). More important, the number of subjects in our experiment was either similar to or greater than that in most previous studies of the magnet effect; for example, in Experiment 2 of Kuhl's (1991) study, there were only 8 adults in each of the prototype and nonprototype conditions. With respect to the precision of data collection and analysis, several aspects of our method (e.g., customization of stimulus sets, the within-subjects nature of our design) were well suited for detecting the interaction of interest, and standard ANOVA techniques were employed. Therefore, we suspect that any lack of power in this experiment was primarily due to a small effect size. In fact, we conducted a power analysis, which yielded an effect size of .03; thus, assuming our experiment was conducted with little error and the effect size is truly this small, a sample of at least 1,000 subjects would be required to detect the effect (Cohen, 1988).

\section{Individual Subjects' Performance}

Recently, Aaltonen et al. (1997) found individual differences in Finnish listeners' categorization of vowels varying in the frequency of $F 2$ as either $/ y /$ or $/ i /$ and in their goodness ratings for stimuli identified as /i/. Subjects were classified as either good categorizers $(n=7)$ or poor categorizers $(n=6)$ on the basis of categorization 
Table 5

Individual Subjects' Mean $d^{\prime}$ Scores and $95 \%$ Confidence Intervals for the Prototype and Nonprototype Conditions as a Function of Preference Group

\begin{tabular}{|c|c|c|c|c|c|c|c|}
\hline \multirow{3}{*}{$\begin{array}{c}\text { Subject } \\
\text { Number }\end{array}$} & \multirow{3}{*}{$\begin{array}{c}\text { Preference } \\
\text { Score }\end{array}$} & \multicolumn{3}{|c|}{ Prototype Condition } & \multicolumn{3}{|c|}{ Nonprototype Condition } \\
\hline & & \multirow{2}{*}{ Mean $d^{\prime}$} & \multicolumn{2}{|c|}{ Confidence Interval } & \multirow[b]{2}{*}{ Mean $d^{\prime}$} & \multicolumn{2}{|c|}{ Confidence Interval } \\
\hline & & & $M$ & $S D$ & & $M$ & $S D$ \\
\hline \multicolumn{8}{|c|}{ High Preference } \\
\hline 1 & 100 & 3.62 & $.02-7.22$ & 7.20 & 3.78 & $.34-7.22$ & 6.88 \\
\hline 6 & $94^{*}$ & 2.48 & $.79-4.16$ & 3.37 & 2.88 & $.60-5.16$ & 4.56 \\
\hline 7 & 88 & 1.75 & $-1.22-4.72$ & 5.94 & 4.39 & $.94-7.84$ & 6.90 \\
\hline 8 & $100^{*}$ & 4.53 & $1.23-7.84$ & 3.31 & 5.18 & $2.22-8.13$ & 5.91 \\
\hline 9 & $88^{*}$ & 4.20 & $1.23-7.16$ & 5.93 & 4.65 & $2.51-6.78$ & 4.27 \\
\hline 10 & 94 & 2.18 & $.48-3.88$ & 3.40 & 2.80 & $.29-4.31$ & 3.02 \\
\hline 18 & 94 & 1.88 & $.35-3.40$ & 3.05 & 1.67 & $-.66-4.02$ & 4.68 \\
\hline 20 & 88 & 1.62 & $-.54-3.78$ & 4.32 & 1.77 & $-1.95-5.48$ & 7.43 \\
\hline 21 & $94^{*}$ & 2.05 & $.33-3.77$ & 3.44 & 3.27 & $.68-5.86$ & 5.18 \\
\hline 24 & 94 & 2.45 & $-.65-5.54$ & 6.19 & 3.30 & $1.14-5.47$ & 4.43 \\
\hline 26 & 94 & 3.40 & $.78-6.01$ & 5.23 & 3.50 & $.92-6.09$ & 5.17 \\
\hline 34 & $88^{*}$ & 4.42 & $2.74-6.10$ & 3.36 & 3.40 & $.83-6.15$ & 5.32 \\
\hline$M$ & & 2.88 & & 4.56 & 3.38 & & 5.31 \\
\hline$S D$ & & 1.09 & & 1.45 & 1.05 & & 1.28 \\
\hline \multicolumn{8}{|c|}{ Low Preference } \\
\hline 4 & 6 & 3.34 & $.56-6.12$ & 5.56 & 3.03 & $.02-6.03$ & 6.01 \\
\hline 5 & $81^{*}$ & 2.64 & $.40-4.90$ & 4.50 & 3.66 & $.18-7.13$ & 6.95 \\
\hline 13 & $50^{*}$ & 4.00 & $1.24-6.76$ & 5.52 & 3.68 & $.83-6.53$ & 5.70 \\
\hline 14 & 63 & 3.81 & $.70-6.91$ & 6.21 & 3.92 & $1.29-6.55$ & 5.26 \\
\hline 15 & 81 & 2.58 & $.90-4.25$ & 3.35 & 3.70 & $2.28-5.12$ & 2.84 \\
\hline 16 & $75^{*}$ & 3.50 & $-1.38-8.37$ & 9.75 & 4.48 & $1.50-7.45$ & 5.95 \\
\hline 17 & $63^{*}$ & 3.43 & $1.41-5.44$ & 4.03 & 3.56 & $1.66-5.52$ & 3.86 \\
\hline 28 & 75 & 3.29 & $-.20-6.78$ & 6.98 & 2.64 & $-1.52-6.80$ & 8.32 \\
\hline 29 & 81 & 2.85 & $-1.14-6.83$ & 7.97 & 3.64 & $1.56-5.71$ & 4.15 \\
\hline 33 & $63^{*}$ & 3.22 & $.03-6.42$ & 6.39 & 3.09 & $.21-5.97$ & 5.76 \\
\hline 36 & $56^{*}$ & 1.28 & $-1.74-4.29$ & 6.03 & 2.27 & $.003-4.54$ & 4.54 \\
\hline 37 & 75 & 0.62 & $-1.19-2.46$ & 3.65 & 0.72 & $.45-.98$ & 0.53 \\
\hline$M$ & & 2.88 & & 5.83 & 3.20 & & 4.99 \\
\hline$S D$ & & 1.01 & & 1.85 & 0.98 & & 2.02 \\
\hline
\end{tabular}

Note-The upper and lower limits (and the range) of each confidence interval are shown.

*Group 1 (Up); see the Method section.

consistency (identification of most continuum members as $/ y /$ or $/ \mathrm{i} /$ on $75 \%$ or more of the trials) and boundary width (narrow or wide). The $/ \mathrm{i}$ / prototype was located near the $/ y-i$ / boundary for good categorizers, whereas it was located further along the $F 2$ continuum (the frequency of $F 2$ was higher) for poor categorizers. Good categorizers found it more difficult to detect small $F 2$ deviations from their prototype than from a nonprototype $/ \mathrm{i} /$ - that is, a magnet effect was observed. In contrast, poor categorizers found it more difficult to detect deviations from the nonprototype than from their prototype. For each group, nonprototypes were located near the other group's prototypes. Thus, although there was individual variation in prototype selection, all the subjects displayed poorest sensitivity for within-category contrasts in the same region of the $F 2$ continuum-namely, near the $/ y-i /$ boundary.

At the suggestion of one reviewer, we asked whether there were also individual differences in the consistency of our subjects' prototype selection and, if so, whether discrimination performance varied as a function of these differences. First, the subjects were classified with respect to their consistency in selecting their prototype over the nonprototype (see the Method section): Those with a preference score of $88 \%$ or greater $(n=12)$ were assigned to a high-preference group; those with a score of less than $88 \%(n=12)$ were assigned to a low-preference group (see Table 5). ${ }^{3}$

Next, we calculated $95 \%$ confidence intervals for each subject's mean $d^{\prime}$ scores (collapsed over distance) in the prototype and nonprototype conditions (see also Table 5). A 2 (preference group, high or low) $\times 2$ (condition, prototype, nonprototype) ANOVA revealed a significant interaction $[F(1,22)=4.79, p<.05]$. According to simple effects tests, there was some tendency for the confidence intervals of the high-preference group to be more narrow than those of the low-preference group in the prototype condition $[M=4.56$ vs. $5.83 ; F(1,37)=3.42, p=.07]$; no other comparisons approached significance.

We also conducted a 2 (preference group, high or low) $\times 3$ (condition, prototype, nonprototype, foreign) $\times 4$ (distance, $15,30,45$, or 60 mels) ANOVA on subjects' $d^{\prime}$ scores. This analysis revealed main effects of condition $[F(2,44)=4.03, p<.025]$ and distance $[F(3,66)=215.63$, 

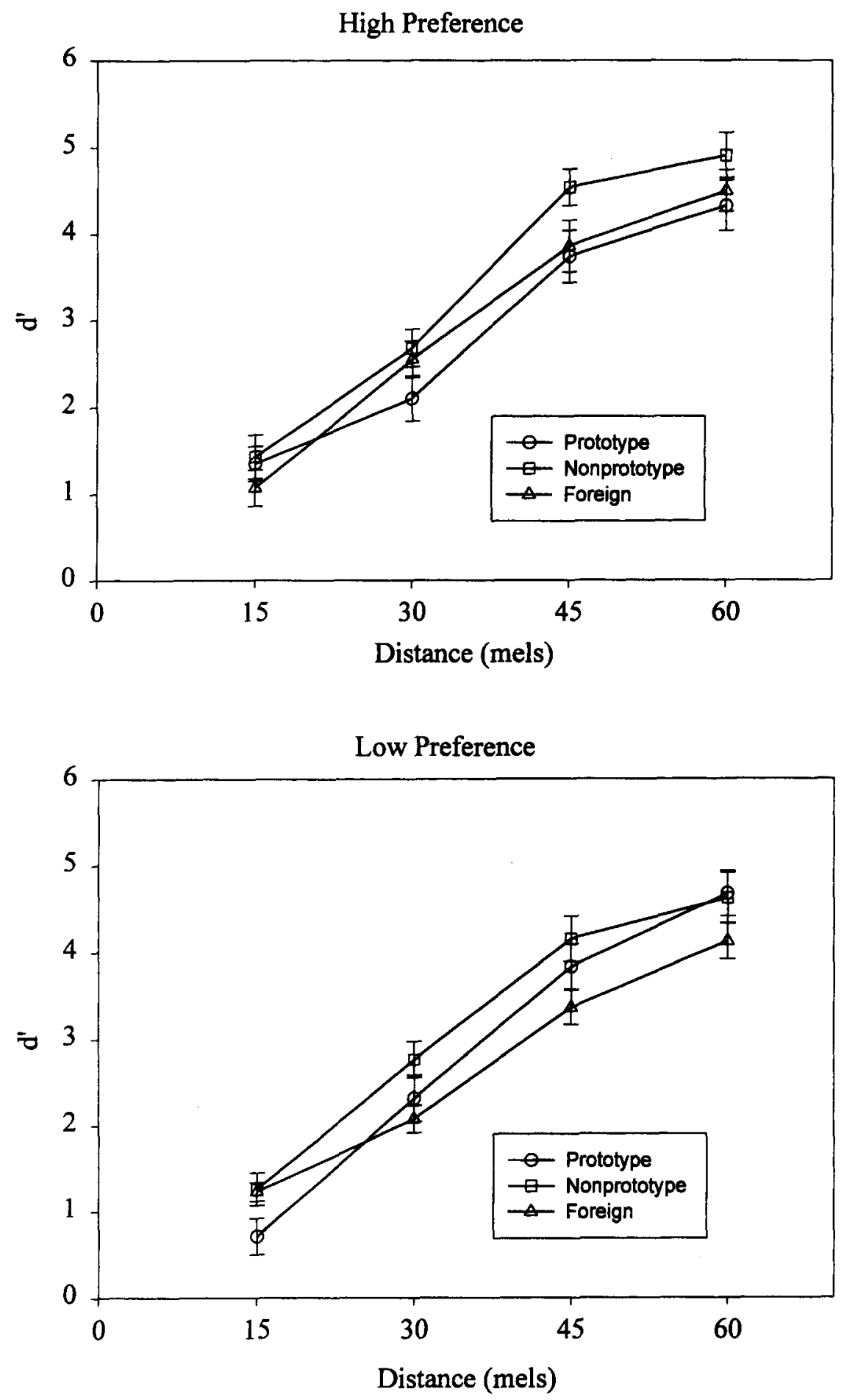

Figure 6. High- and low-preference subjects' mean $d^{\prime}$ scores (and standard errors) as a function of condition and distance in Experiment 2.

$p<.0001]$, as well as a significant three-way interaction $[F(6,132)=2.29, p<.04]$. To examine the nature of this interaction, separate 3 (condition) $\times 4$ (distance) ANOVAs for the high- and low-preference groups were conducted.

The analysis for the high-preference group (see upper panel of Figure 6) revealed only a main effect of distance
$[F(3,33)=144.92, p<.0001]$. The analysis for the lowpreference group (see lower panel of Figure 6) revealed a marginal effect of condition $[F(2,22)=2.86, p=.08]$, a significant effect of distance $[F(3,33)=86.07, p<$ $.0001]$ and a significant condition $\times$ distance interaction $[F(6,66)=2.28, p<.05]$. This interaction was largely 


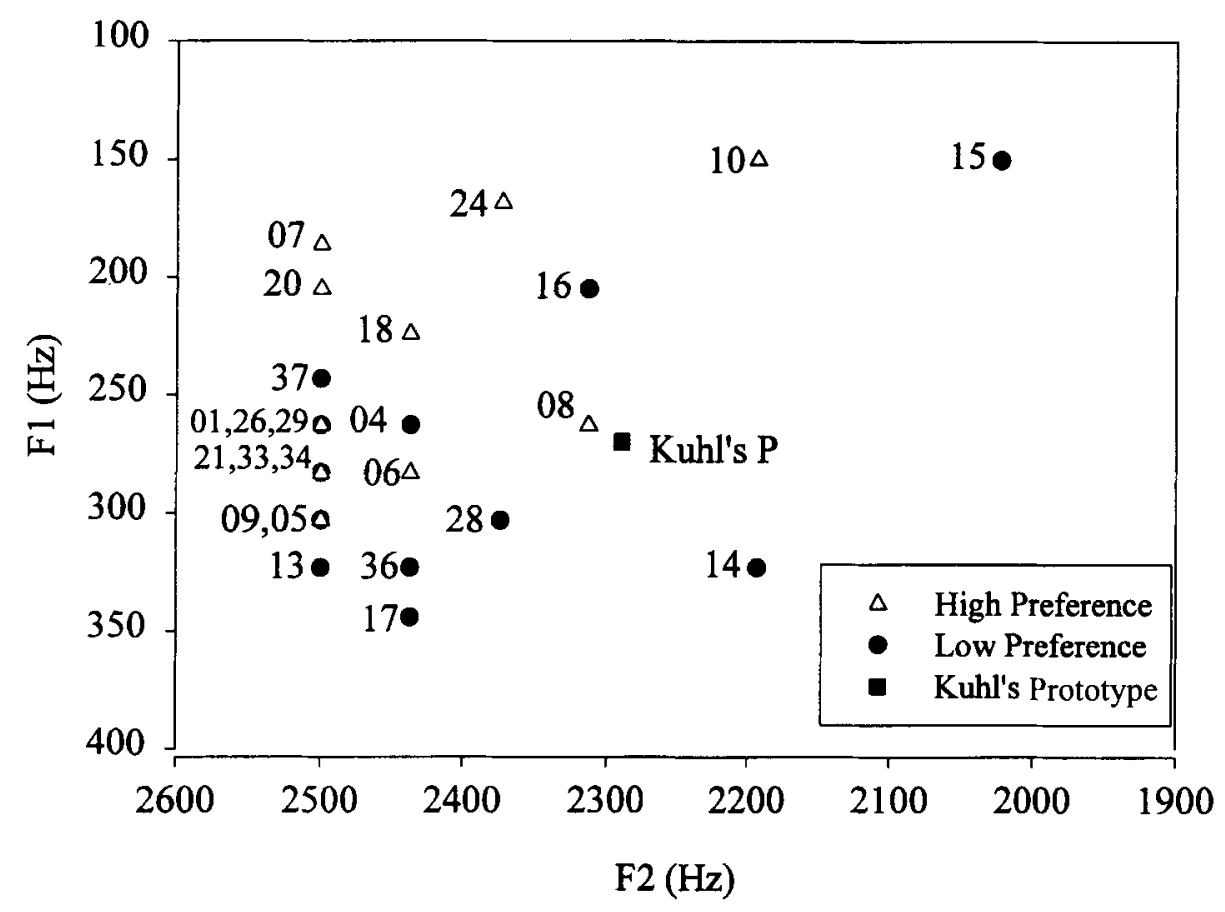

Figure 7. High- and low-preference subjects' prototypes and Kuhl's (1991) prototype.

due to poorer discrimination for the prototype than for the foreign vowel at 15 mels and to the reverse pattern at 60 mels. In fact, when we conducted the ANOVA with only two levels of condition (prototype and nonprototype), the only significant result was a main effect of distance $[F(3,33)=71.48, p<.0001]$.

Finally, there did not appear to be systematic differences in the location of subjects' prototypes as a function of preference group (see Figure 7). We also informally examined discrimination performance for prototype and nonprototype stimuli in various regions within the /i/ portion of the vowel space. This inspection did suggest that $d^{\prime}$ scores, even for 60-mel stimuli, were rather low in the area where $F 1=200-300 \mathrm{~Hz}$ and $F 2=2500-2300 \mathrm{~Hz}$, as compared with the other adjacent areas. Interestingly, this area of apparently weaker discrimination is very close to Kuhl's (1991) prototype. Perhaps, then, most listeners' discrimination performance is intrinsically weak for this part of the vowel space (see Stevens, Liberman, Studdert-Kennedy, \& Ohman, 1969), and this factor has contributed, at least in part, to previous observations of a magnet effect (e.g., to poor discrimination for stimuli to the left of the prototype in Experiment 2 of Iverson \& Kuhl, 1995).

In summary, we found only weak evidence of a magnet effect in our main analysis of all subjects' performance $(n=24)$; that is, discrimination was poorer for the $\mathrm{P}$ condition than it was for the NP condition, but no condition $x$ distance interaction was observed. Closer inspection of subjects' performance as a function of consistency of prototype selection (high or low preference) did not re- veal any additional support for a magnet effect. In fact, the high-preference group, when considered by itself, did not even show a main effect of condition, and the lowpreference group only tended to show this effect.

\section{GENERAL DISCUSSION}

Our study employed both standard and novel procedures in evaluating the perceptual magnet effect. According to this effect, category typicality or goodness affects perception in such a way that discrimination is reduced, especially near the prototype or best exemplar of a given phonetic category (Kuhl, 1991, 1993a, 1993b, 1993c). However, recent studies have found that Kuhl's (1991) nonprototype is consistently labeled as /e/ or "not /i/" (Iverson \& Kuhl, 1995; Lively \& Pisoni, 1997; Sussman \& Lauckner-Morano, 1995). Therefore, Experiment 1 of the present study was conducted to ensure that both prototype and nonprototype referents, as well as their vector stimuli, fell within a given subject's / $i$ / category. We found that there was substantial agreement among subjects as to which stimuli made up the / $/$ / category. Still, there was clear individual variation in the perceived outer limits of this category, as well as in the precise location of the best exemplar or prototype.

To date, there has been a paucity of research examining individual differences in prototype selection for a particular phonetic category and any associated effects on perception (but see Aaltonen et al., 1997; Johnson et al., 1993; Lively \& Pisoni, 1997; Miller \& Volaitis, 1989; Samuel, 1982; Volaitis \& Miller, 1992). In particular, the 
majority of studies in which the perceptual magnet effect was examined have employed a single "one-size-fits-all" vowel prototype based on Peterson and Barney's (1952) mean production data (Grieser \& Kuhl, 1989; Iverson \& Kuhl, 1995; Kuhl, 1991; Kuhl et al., 1992; Sussman \& Lauckner-Morano, 1995), even though speakers of the same language and even the same dialect can differ substantially in their vowel productions (see Hillenbrand, Getty, Clark, \& Wheeler, 1995; Joos, 1948; Labov, 1991; Labov \& Ash, 1997; Peterson \& Barney, 1952). Recently, however, Lively and Pisoni (1997) had subjects rate Kuhl's (1991) prototype and nonprototype stimulus sets separately for category goodness and then used these ratings to synthesize customized stimulus sets for a discrimination experiment. Our Experiment 1 results concur with their rating results, in that our subjects chose prototypes with higher $F 2$ values than those of Kuhl's prototype (see also Iverson \& Kuhl, 1995; Sussman \& Lauckner-Morano, 1995). Furthermore, in both studies, a majority of subjects selected disparate stimuli as their prototype: In Lively and Pisoni's study, 21 of the 33 stimuli in Kuhl's prototype set were rated as "best" by at least 1 subject; in our study, 16 of 24 subjects chose different prototypes, thus demonstrating a lack of consensus regarding prototype location (see, also, Aaltonen et al., 1997; Johnson et al., 1993). However, whereas Lively and Pisoni's stimulus sets were restricted to the values used by Kuhl (1991), our subjects selected their prototype from a fine-grained grid of vowels synthesized in difference limens for both $F 1$ and $F 2$. In addition, in contrast to previous studies, subjects from diverse dialectal backgrounds were explicitly chosen to participate in our study, so that possible prototype differences would be maximized. We found that American English speakers do indeed differ in their prototype selections-even subjects from the same state (viz., Alabama).

Lively and Pisoni (1997) have stressed that two criteria must both be met to provide evidence of the perceptual magnet effect. First, phonetic categories must display internal structure as reflected by systematically better goodness ratings for some exemplars than for others. Second, discrimination must be poorer for category members that closely match the prototype than for those that do not - that is, discriminability should vary inversely with prototypicality. As was noted in the introduction, a main effect of condition (poorer discrimination for prototype than for nonprototype stimuli) has sometimes been considered sufficient to satisfy this second requirement (e.g., Aaltonen et al., 1997; Lively \& Pisoni, 1997). However, the strongest support for the operation of a magnet effect is afforded by a condition $\times$ distance interaction, whereby discrimination is especially poor for stimuli close to the prototype (see, in particular, Kuhl, 1991).

Our results met the first criterion outlined by Lively and Pisoni (1997) and concur with previous findings, in that subjects selected and rated some vowel stimuli as more prototypic of the / $\mathrm{i}$ / category than they did others (Experiment 1). In addition, at least half of our subjects demonstrated a strong preference for their / i / prototype over a nonprototype stimulus (Experiment 2). With respect to the second criterion, we did observe poorer overall discrimination for the prototype than for the nonprototype condition, but failed to find any evidence of a condition $X$ distance interaction. This was the case even though various aspects of our method, including the use of customized stimulus sets and a within-subjects design, would be expected to enhance the likelihood of detecting such an effect. Thus, our discrimination results provide only rather weak support for a magnet effect.

Lively and Pisoni (1997) found even less support for a magnet effect in their subjects' discrimination performance. In Experiment 2 of their study, one condition employed prototype and nonprototype stimulus sets based on individual subjects' goodness ratings; the other condition employed Kuhl's (1991) prototype and nonprototype stimuli. In neither condition was there a difference in discrimination for the prototype and nonprototype sets (see also Experiment 3). However, whereas Kuhl (1991) observed similar performance across stimulus vectors, Lively and Pisoni found that subjects' discrimination was poorer for stimuli that varied in the $F 2$ dimension only, thus raising the question of whether the mel scale is the appropriate unit for equating psychophysical distance between vowel stimuli. Unfortunately, the present results do not speak to this issue, since our subjects participated in one of two groups (Up or Down), both of which employed stimuli with decreasing $F 2$ values only.

An ancillary finding of Lively and Pisoni's (1997) was that subjects' goodness ratings were context dependent (see also Iverson \& Kuhl, 1995). Specifically, Kuhl's (1991) prototype was given the highest rating overall when it was embedded in the nonprototype stimulus set but a lower rating when it was embedded in the prototype stimulus set. Similarly, other studies have shown that the internal structure of phonetic categories can vary across such dimensions as speaking rate (Jusczyk, 1993; Miller \& Volaitis, 1989; Volaitis \& Miller, 1992). In Experiment 1 of our study, however, a method-of-adjustment procedure was employed, allowing each subject to sample as many stimuli as were needed to locate their prototype before participating in Experiment 2, and only subjects who were consistent in their prototype selection participated in this experiment. Therefore, it seems unlikely that context or stimulus set effects had a major influence on our discrimination results. Still, we agree with Lively and Pisoni that a better specification is needed of the nature of any prototype representations for speech and of how such representations function in different contexts.

To the extent that stimuli in the nonprototype condition were more discriminable than those in the prototype condition, our discrimination results are more consistent with those of Iverson and Kuhl (1995) and of Sussman and Lauckner-Morano (1995) than they are with Lively and Pisoni's (1997) results. However, our study differed from all of these studies in several important ways. First, individual differences were found in the values of $F 1$ and 
F2 needed to delimit the / $\mathrm{i}$ / portion of the vowel space for subjects representing diverse dialects. Second, our subjects selected their own prototype from an array of stimuli that varied in difference limens. Third, a foreign vowel referent and variants were included in our discrimination experiment. Unexpectedly, we found that discrimination was reduced for this condition, as well as for the prototype one, relative to the nonprototype condition. Moreover, discrimination performance was not poorer for the prototype than for the foreign condition, as was predicted by Kuhl's (1991, 1993a, 1993b, 1993c) NLM theory. The latter result was particularly surprising, because previous research has shown that prototypes arise from experience with a particular language quite early in development; that is, 6-month-old American and Swedish infants display a magnet effect, but only for vowels in their respective native languages (Kuhl et al., 1992).

In light of these results with infants, English-speaking adults would not be expected to have a prototype for the foreign vowel $/ y /$. On the one hand, then, our results might be taken to indicate that overall reduced discriminability, as in our prototype and foreign versus nonprototype conditions, is not sufficient to indicate a magnet effect; rather, as was outlined previously, discrimination must be especially poor for stimuli that are close to the prototype and that have been judged to be good category exemplars. On the other hand, the discrepancy between the results of our discrimination experiment (the first with adults to have included a foreign condition) and those of Kuhl et al. (1992) might be reconciled by assuming that changes in sensitivity for used and unused portions of the vowel space occur at different points in development. That is, as claimed by NLM theory (Kuhl, 1991, 1993a, 1993b, 1993c), the vowels of one's native language may come to be structured in terms of prototypes by 6 months of age. Thus, the discriminability of good exemplars of a given native category is reduced, whereas the discriminabilty of poor exemplars, as well as exemplars of nonnative categories, is maintained - at least for some time. However, as the phonetic system of the native language continues to develop and stabilize, the perceptual system may have increasing difficulty resolving differences between many, if not all, sounds that reside in unused portions of the vowel space because of their growing "foreignness" (F. Guenther, personal communication, July 30, 1996; see, also, Flege, 1992). Perhaps, then, there is a different timeline involved for reductions in sensitivity for various regions of the vowel space. This reduction may occur quickly (in early infancy) for areas of heavy traffic, or what Kuhl (1993a) has referred to as "hot spots," but more slowly (beyond infancy) for less well traveled, "cold spots."

Guenther and Gjaja (1996) have recently developed a neural network model that offers a rather different account of how the perceptual magnet arises. According to their model, exposure to the particular distribution of sounds in the native language from early infancy leads to nonuniformities in the distribution of firing preferences of auditory neural map cells, and it is these nonuniformities that underlie the magnet effect. By this account, the effect is a simple perceptual phenomenon, rather than a higher level one involving linguistic categories or prototype representations that are stored in memory (see, also, Sussman \& Lauckner-Morano, 1995).

Lively and Pisoni (1997) argue that a more rigorous definition of the nature of such prototype representations is needed, if this construct is to be of further theoretical utility, particularly in helping to solve the perceptual invariance problem. Research examining the consequences of how precisely this construct is operationalized is also essential. Indeed, not all of our subjects (only 24 of 37) met the fairly liberal criteria for prototype selection that we adopted, and only half of these (12 of 24) exhibited a strong preference for their prototype over a nonprototype /i/. To date, however, only a handful of experiments have attempted to have subjects select a prototype for a particular phonetic category and examined individual differences in their selections (see Aaltonen et al, 1997; Johnson et al., 1993; Lively \& Pisoni, 1997; Miller \& Volaitis, 1989; Samuel, 1982). Therefore, there was little precedent on which to base our criteria for prototype selection. Perhaps, employing natural vowel tokens or using information from subjects' own production data would yield a higher number of subjects with clear-cut prototypes and even a different pattern of discrimination results. This issue of prototype operationalization is only one of many important topics that should be addressed in further research. Of course, research with other vowels is crucial, since studies of the perceptual magnet effect have thus far been limited primarily to $/ \mathrm{i} /$ and $/ \mathrm{y} /$ (but see Davis \& Kuhl, 1994; Iverson \& Kuhl, 1996).

In summary, we assessed three predictions that derive from Kuhl's (1991, 1993a, 1993b, 1993c) NLM theory and that are associated with the perceptual magnet effect. Specifically, we asked whether subjects exhibited better discrimination overall for stimuli in a nonprototype than in a prototype condition, whether discrimination was especially poor for stimuli close to their prototype (i.e., whether a condition $\times$ distance interaction obtained), and whether discrimination for foreign vowel stimuli was better than that for stimuli in the prototype condition (and similar to that for stimuli in the nonprototype condition). Only the first prediction was confirmed, and thus, only weak evidence for the operation of a magnet effect was observed, when prototype and nonprototype stimulus sets were customized for subjects. We also found considerable variation in the values of $F 1$ and $F 2$ needed to delimit the /i/ portion of the vowel space for our subjects, who represented diverse dialects of American English. Our subjects also selected quite disparate stimuli as their / $\mathrm{i}$ / prototype. These results highlight the need to further assess and account for individual differences in vowel perception. 


\section{REFERENCES}

Aaltonen, O., Eerola, O., Hellstrom, A., Uusipaikka, E., \& Lang, A. H. (1997). Perceptual magnet effect in light of behavioral and psychophysiological data. Journal of the Acoustical Society of America, 101, 1090-1105.

COHEN, J. (1988). Statistical power analysis for the behavioral sciences. Hillsdale, NJ: Erlbaum.

Davis, K., \& KUHL, P. K. (1994). Test for the magnet effect for American English $/ \mathrm{k} /$ and $/ \mathrm{g} /$. Journal of the Acoustical Society of America, 95, 2976.

DoOlEy, G., \& MoORE, B. (1988). Detection of linear frequency glides as a function of frequency and duration. Journal of the Acoustical Society of America, 84, 2045-2057.

FANT, G. (1973). Speech sound and features. Cambridge, MA: MIT Press.

Flanagan, J. L. (1955). A difference limen for vowel formant frequency. Journal of the Acoustical Society of America, 27, 288-291.

FLEGE, J. E. (1992). Speech learning in a second language. In C. A. Ferguson, L. Menn, \& C. Stoel-Gammon (Eds.), Phonological development: Models, research, implications (pp. 565-604). Timonium, MD: York Press.

FLEGE, J. E., \& SCHMIDT, A. (1995). Native speakers of Spanish show a rate-dependent processing of English stop consonants. Phonetica, 52, 90-111.

GRIESER, D., \& KUHL, P. K. (1989). Categorization of speech by infants: Support for speech-sound prototypes. Developmental Psychology, 25, 577-588.

GuENTHER, F. H., \& GJAJA, M. N. (1996). The perceptual magnet effect as an emergent property of neural map formation. Journal of the Acoustical Society of America, 100, 1111-1121.

Hillenbrand, J., GetTy, L. A., Clark, M. J., \& Wheeler, K. (1995). Acoustic characteristics of American English vowels. Journal of the Acoustical Society of America, 97(5, Pt. 1), 3099-3111.

IVERSON, P., \& KUHL, P. K. (1995). Mapping the perceptual magnet effect for speech using signal detection theory and multidimensional scaling. Journal of the Acoustical Society of America, 97, 553-562.

IVERSON, P., \& KUHL, P. K. (1996). Influences of phonetic identification and category goodness on American listeners' perception of $/ \mathrm{r} /$ and 11\%. Journal of the Acoustical Society of America, 99, 1130-1140.

Johnson, K., Flemming, E., \& Wright, R. (1993). The hyperspace effect: Phonetic targets are hyperarticulated. Language, 3, 505-528.

Joos, M. (1948). Acoustic phonetics (Linguistic Society of America, Language Monograph 23). Baltimore: Waverly Press.

JUSCZYK, P. W. (1993). Some reflections on developmental changes in speech perception and production. Journal of Phonetics, 21, 109-116.

KLATT, D. H. (1980). Software for a cascade/parallel formant synthesizer. Journal of the Acoustical Society of America, 67, 971-995.

KuHL, P. K. (1991). Human adults and human infants show a "perceptual magnet effect" for the prototypes of speech categories, monkeys do not. Perception \& Psychophysics, 50, 93-107.

KuHL, P. K. (1993a). Early linguistic experience and phonetic perception: Implications for theories of developmental speech perception. Journal of Phonetics, 21, 125-139.

KUHL, P. K. (1993b). Infant speech perception: A window on psycholinguistic development. International Journal of Psycholinguistics, 9, 33-56.

KuHL, P. K. (1993c). Innate predispositions and the effects of experience in speech perception: The native magnet theory. $\ln \mathrm{B}$. de BoyssonBardies, S. de Schonen, P. Jusczyk, P. McNeilage, \& J. Morton (Eds.), Developmental neurocognition: Speech and face processing in the first year of life (pp. 259-274). Dordrecht: Kluwer.
Kuhl, P. K., Williams, K. A., Lacerda, F., STeVens, K. N., \& LiNDBLOM, B. (1992). Linguistic experience alters phonetic perception in infants by 6 months of age. Science, 255, 606-608.

LABOV, W. (1991). The three dialects of English. In P. Eckert (Ed.), New ways of analyzing sound change (pp. 1-43). San Diego: Academic Press.

LABOV, W., \& Ash, S. (1997). Understanding Birmingham. In C. Bernstein, T. Nunnally, and R. Sabino (Eds.), Language variety in the South revisited (pp. 508-573). Tuscaloosa: University of Alabama Press.

LADEFoged, P. (1962). Elements of acoustic phonetics. Chicago: University of Chicago Press.

LiVELY, S., \& PISONI, D. (1997). On prototype and phonetic categories: A critical assessment of the perceptual magnet effect in speech perception. Journal of Experimental Psychology: Human Perception \& Psychophysics, 23, 1665-1679.

Macmillan, N. A., \& Creelman, C. D. (1991). Detection theory: A user's guide. New York: Cambridge University Press.

Miller, J. L., \& Volaitis, L. E. (1989). Effect of speaking rate on the perceptual structure of a phonetic category. Perception \& Psychophysics, 46, 505-512.

Peterson, G. E., \& Barney, H. L. (1952). Control methods used in the study of vowels. Journal of the Acoustical Society of America, 25, 175-184.

Rosch, E. (1975). Cognitive reference points. Cognitive Psychology, 7, 532-547.

Samuel, A. G. (1982). Phonetic prototypes. Perception \& Psychophysics, 31, 307-314.

Smith, E. E., \& Medin, D. L. (1981). Concepts and categories. Cambridge, MA: Harvard University Press.

Stevens, K. N., Liberman, A. M., Studdert-Kennedy, M., \& OHMAN, S. E. (1969). Crosslanguage study of vowel perception. Language \& Speech, 12, 1-23.

Sussman, J. E., \& LAUCKNER-Morano, V. J. (1995). Further tests of the "perceptual magnet effect" in the perception of [i]: Identification and change/no-change discrimination. Journal of the Acoustical Society of America, 97, 539-552.

Volaitis, L. E., \& Miller, J. L. (1992). Phonetic prototypes: Influences of place of articulation and speaking rate on internal structure of voicing categories. Journal of the Acoustical Society of America, 92, 723-735.

\section{NOTES}

1. Only males participated, because the present study was part of a larger project in which we also examined vowel productions and sought to limit $F 0$ differences.

2. An analysis with Subject 4's data excluded yielded essentially the same results; that is, only main effects of condition $[F(2,42)=4.48, p<$ $.02]$ and distance $[F(3,63)=206.39, p<.0001]$ were found, and the nature of each effect was similar to that described in the text.

3. We also considered the consequences of employing an alternate definition of consistency that was based on the modal values that obtained in Experiment 1 and were used to define each subject's prototype (see Table 3 ). Specifically, those subjects who selected a stimulus seven or more times as their prototype were classified as highly consistent $(n=11)$; those who selected a stimulus fewer than seven times were classified as less consistent $(n=13)$. This classification yielded differences that were even less pronounced than those reported in the main text

(Manuscript received March 28, 1997; revision accepted for publication March 29, 1998.) 